\title{
CONSIDERATIONS FOR EMPLOYING SERVER VIRTUALIZATION TECHNOLOGIES
}

\author{
Darla Sligh, University of Maryland, darla.sligh@faculty.umuc.edu \\ Theophilus D. Owusu, Keiser University, towusu@keiseruniversity.edu
}

\begin{abstract}
Server virtualization enables a physical computer to support multiple applications logically by decoupling the application from the hardware layer, thereby reducing operational costs and competitive in delivering IT services to their enterprise organizations. IT organizations continually examine the efficiency of their internal IT systems and their IT organizational processes. Researchers suggest that server virtualization technology is a disruptive innovation, but IT professionals must manage the decision process regarding server virtualization to ensure success because a poor employment of server virtualization can jeopardize the effectiveness of service delivery to its enterprise organizations. Today, IT professionals have only to read the latest news or perform pilot analysis to identify the employment of the server virtualization technology. This qualitative study explores the factors that influence the decision-making process regarding the choice to employ server virtualization technologies within organizations.
\end{abstract}

Keywords: Server Virtualization, Information Technology (IT), IT Professionals, IT Infrastructure, Server, Virtualization, Implementation.

\section{INTRODUCTION}

With the advent of technology, business organizations as well as information technology (IT) organizations are relying on and implementing a mixture of applications to support their organizational goals. Over the years, this varying mix of applications has rapidly increased, causing the simultaneous growth in the number of IT infrastructure services requests (i.e., servers, storage, and network communication devices) required to support these applications [6]. Because interruptions in IT services can significantly affect an organization's success, IT organizations are consistently challenged to ensure that the IT infrastructure is reliable, dependable, and available. In addition to the rapid onset of enterprise requests, the evolution of IT infrastructure has forced IT organizations to become more cost effective and competitive in delivering IT services to their enterprise organizations [16, 26].

The purpose of this study is to develop heuristics, which IT professionals can advantageously make use of during the employment of server virtualization technologies within their organizations. These heuristics identify the components of the employment process which includes the attributes that influence IT professionals' decisions, options they considered, their choices from amongst those options, and their reason for selecting those options, enabling a multi-criteria decision process that impacts employing server virtualization technologies within an organization. As a result, in this study, the decision making practices of a sample of twenty IT professionals were extracted to ascertain if these decisions replicate current decision practices and are justified based on a reasonable set of attributes, rather than an ad hoc approach to decision making.

\section{Background}

In the 1990s until the early 2000s, the trend in the data center was to support the organization by providing inexpensive and powerful $\mathrm{x} 86$ server configurations separated and dedicated to specific applications. A decentralization management approach hosted these applications because of the use of a software development life cycle (SDLC) as a structured approach to application development that often required a dedicated server configuration to host separate and distinct iterations of an application (i.e., development, test, and production). The commodization of servers and computer hardware and the ease of server maintenance patches or upgrades could be applied without compromising or affecting other applications or operating systems, giving additional reasons for decentralizing the management of the application server-hosting environment [5, 7]. Also in the same period, the late 1990s, organizations vastly increased usage of a mixture of applications such as Web services, database access, transaction processing systems, decision support systems, distributed file services, and high-performance computing, 


\section{Issues in Information Systems \\ Volume 15, Issue I, pp. 418-429, 2014}

to support their business needs. This increase of application usage caused an exponential growth in application hosting servers, which caused the need for organizations to consolidate their server platforms within a centralized data center [6]. This is commonly referred to as server sprawl, which is a situation or the trend in server growth in which multiple, under-utilized servers take up more space and consume more resources than can be justified by their workload $[1,5]$.

In the 2000s, organizations noticed that this intensified server sprawl caused an increase in power consumption requirements, operational inefficiencies, and maintenance overhead. IT organizations sought ways to reduce the server sprawl impact because it has spawned the following issues, underutilization of hardware, lack of space in data centers and increased operational costs $[5,7,14,17,24]$.

Consequently, many IT organizations were utilizing server virtualization technologies to consolidate applications within servers to avoid server sprawl that would reduce the requirements for additional server hardware, power spending, and data center space [16].

\section{RESEARCH METHODOLOGY}

The purpose of this study is to explore the IT professionals' perspective on decisions to employ server virtualization technologies within the organization. In seeking a better understanding of their decision process, the study addressed two research questions:

- R1) What do IT professionals see as the relevant factors influencing their choice to employ server virtualization technologies within an IT organization?

- $\quad$ R2) How are decisions made when employing server virtualization technology within an organization?

Further, this study will demonstrate that the use of the Multi-attribute Utility Theory (MAUT) describes the current server virtualization decision practices.

\section{Qualitative Research Approach}

Qualitative studies such as this research seek to understand the contextual nature of the research participant as well as adopt an interpretive stance of the participant. The qualitative researcher is committed to study the lived experiences of the participants, to interpret how meanings are formed through and in culture, and to discover rather than test a theory or pattern $[3,10,11]$. This study uses descriptions of IT professionals' decisions for employing server virtualization technologies to identify relevant factors influencing their decisions, and to determine if their current decision practices replicates a known decision analysis approach in order to improve decision support. Continuing research may build on this exploration to build theory and to test value of relevant factors that influence decisions for employing technologies within IT organizations.

Qualitative methodology establishes design flexibility; facilitates interaction between researcher and participants; and implies an emphasis on exploration, discovery, and description. The objectives are generally focused on extracting and interpreting the meaning of experience [3,12]. In contrast, quantitative research is applied to describe current conditions, investigating relationships with emphasis on deductive reasoning and cause and effect thinking concerned with testing or confirming hypotheses about an experience $[2,10,11]$.

\section{Research Sample: The participants}

In order to capture rich data, the researcher sought the opinions of IT professionals who experienced employment of server virtualization technologies. A purposeful sampling procedure was used to select this study's sample. The researcher sought to locate individuals who represented a variety of IT organizations. Thus, drawing from the researcher's working relationships, the participant used quota and snowballing sampling procedures to identify participants for this study.

First, the quota sampling strategy described by Copernicus Consulting, [8] and Marshal [20] was employed, whereby the researcher determined what the sample looked like in terms of specific qualities, creating quotas based on those qualities, and then selects people for each quota. Therefore, the researcher required the participants to be IT professionals who had experience in the following IT roles: IT security, IT architects, CIO, operations manager, systems engineer, IT project managers, and/or system and network administrators. Within an IT organization, these 


\section{Issues in Information Systems \\ Volume 15, Issue I, pp. 418-429, 2014}

IT professional roles represent the selection, design, installation, management, or evaluation of physical devices [28]. The researcher also established the following criteria: 1) Have at least five-- years of experience as an IT professional in the aforementioned roles. IT professionals are practitioners with specific skills rooted in principles of computer organization, operating systems, and network systems, with appropriate qualifications; belong to a regulated body; undergo continuous development; operate a code of conduct; and recognize personal accountability [4]. The five year criterion coincides with common professional accreditation requirements of the IT industry; for example, Project Management Institute (PMI) and Certified Information Systems Security Professionals (CISSP) require credentials of a minimum of five years [22]. 2) Have a direct involvement in employing (e.g., selecting, managing, implementing, or evaluating) virtualization technologies projects.

Secondly, snowballing sampling strategy, sometimes referred to as network or chain sampling [20, 21], was used, whereby participants were asked to recommend other IT professionals within their organizations that have employed server virtualization technologies. Because of the researcher's extensive IT professional experience, the researcher had direct involvement in the development of data center strategies and employment processes; and the researcher was able to develop close working relationships with IT professionals who represented various commercial organizations, governmental agencies, and other professionals representing companies that held service contracts with the U. S. Government Agency program. The researcher drew from these relationships and used the snowballing sampling technique to recruit eight IT professionals as participants for this study.

In addition, the researcher asked a deputy CIO for the U. S. government agency program, the senior director for a northern Virginia non-profit that advises the federal government, and the chief security officer (CSO) for a nonprofit community-based health organization headquartered in northern Maryland, to recruit participants from their organizations for this study. The researcher received permission from these organizations to interview staff, to inform them that the process is voluntary, and to request permission to contact participants for follow up or clarification, if necessary. The researcher also signed non-disclosure agreements (NDA) stating that the researcher will not disclose and will protect confidential information of the organization. During the week of September 21, 2009 , the researcher announced during two separate U. S. governmental agency program IT meetings that the researcher was seeking participants for the study. The researcher described the purpose of the study, invited participation, and requested a convenient date and time for face-to-face or phone interviews. Because of these meetings, five IT professionals volunteered to participate in this study.

After the researcher obtained permission from the senior director for a northern Virginia non-profit that advises the federal government to recruit participants at his company, the researcher searched the company's knowledge-base for those IT professionals who attended virtualization seminars. The researcher performed an additional knowledge base query to further identify the seminar attendees' resumes in order to determine if any of these attendees meet the criteria for being a participant in this study. Upon reviewing these resumes, the researcher applied the aforementioned criteria to select potential participants in this study. The researcher identified 15 potential participants and emailed recruitment letters; five IT professionals agreed to participate in this study. Finally, the researcher contacted her previous supervisor who is now chief security officer at a non-profit community-based health organization serving the Baltimore/Washington, D. C. region and which is headquartered in northern Maryland. The CSO referred two participants for this study.

In summary, the research sample in this study included 20 IT professionals who met the requirement for supporting IT infrastructure environments as primary stakeholders, such as IT managers, information architects, network engineers, IT security professionals, operations managers, and system administrators in an IT infrastructure implementation project.

\section{Information needed to Conduct the Study}

This grounded theory study focused on 20 IT professionals representing various IT disciplines. In order to understand the IT professionals' perspectives regarding employing server virtualization technologies, three research questions were explored. The information required to answer these questions was determined by the conceptual framework and fell into the perceptual category and the theoretical category.

- $\quad$ Perceptual category - indicates the goals, attributes, and objectives that influence the IT professional's decision process regarding server virtualization technologies. 


\section{Issues in Information Systems}

Volume 15, Issue I, pp. 418-429, 2014

- Theoretical category - indicates ongoing literature review and comparative analysis that supports theoretical grounding for this study.

\section{Data analysis and Synthesis Process}

Qualitative data analysis is an ongoing artful process involving continual reflection about the data; it involves constant comparative analysis and interpretation that includes the following steps: data preparation, data exploration, reduction of data, and interpretation of data in order to report the findings $[12,15]$. Figure 1 is a data analysis and interpretation design process map, or model [15].

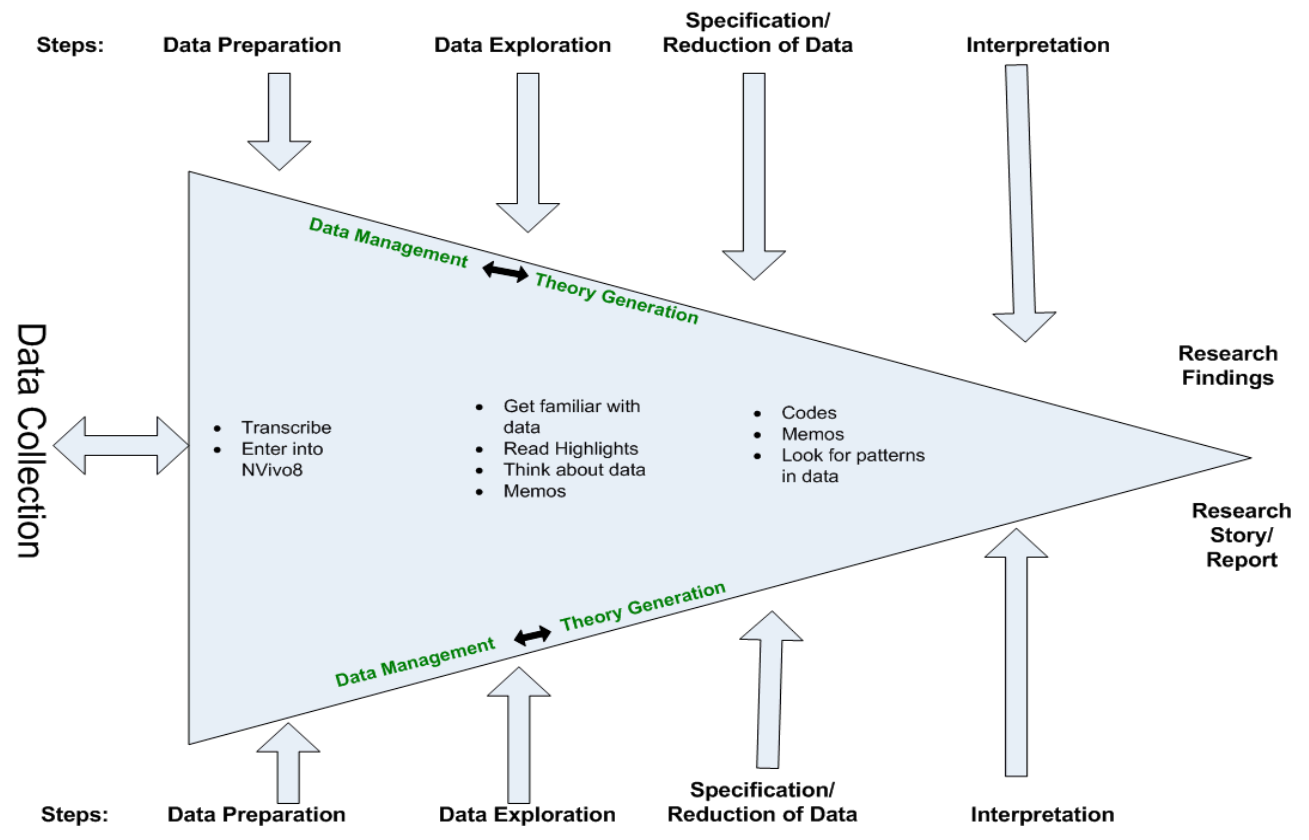

Figure 1. Multi-attribute Utility Theory (MAUT)

Once the interviews are completed, the researcher drew from the grounded theory approach to lift out common patterns and themes, segregating and categorizing based on perspectives, attributes, and goals. For this study, the data analysis and data collection activities were performed in concert to avoid the risk of repetition and to maintain focus [3]. The researcher used the QSR NVivo 8 qualitative analysis tool to capture, manage, shape, and contextualize information; the researcher to apply the ground theory to discover patterns, identify themes, implant coding, and informed delivery of robust information.

Multi-attribute Utility Theory (MAUT) framework is a decision analysis methodology that provides a principle foundation for choices involving multiple criteria $[13,27]$. MAUT is concerned with making tradeoffs among different goals. For example, when buying a computer, the relevant goals might be price, portability, speed, ease of repair, and disk capacity, and therefore the application certainty is known. Another part of utility theory is concerned with making tradeoffs among different goals for different people, therefore maximizing utility over all relevant people. In addition this utility theory is concerned with making tradeoffs among different goals that occur at different times (present versus future). Unlike other decision theory frameworks (within in the Multi-Criteria Decision Making (MCDM), such as Analytic hierarchy process (AHP) Election et Choix Traduisant la Réalité (ELECTRE), or Preference Ranking Organisation Method for Enrichment Evaluations (PROMETHEE) the MAUT also allows the addition of uncertainty of future states (new alternatives) to be consider among tradeoffs, since the future outcomes can affect the decision maker or others [13]. MAUT allows decision makers: 1) to make tradeoffs among different alternatives, current vs future; 2) to set priorities and make the best decision when qualitative aspects of a decision need consideration; 3 ) to reduce complex decisions to a series of one-on-one comparisons that are used to synthesize the results; and 4) to think systematically about identifying, and structuring objectives, about making, vexing value tradeoffs, and about balancing various risks [18]. 
In order to analyze current server virtualization employment practices, to verify if it replicates the Multi-attribute Utility Theory (MAUT) framework, the researcher compared, contrasted, and associated the framework of the MAUT to identify if the current server virtualization decision practices emulate this theoretical approach for decision-making.

The applications and methods of MAUT are presented in the context of certainty as well as uncertainty (requires examination of the degree or probability, to which the decision maker believes of their values) and so this would seem to be an appealing theory to use for framing these approaches. However this study seeks to explore multiple perspectives regarding the employment of server virtualization technologies, the MAUT approach for certainty seems to champion the decision process regarding server virtualization employment. As a result, upon the completion of the data collection process, this study will apply the MAUT approach to that data, in order to determine if the implementation of current server virtualization decision practices describe the MAUT approach.

Table 1 describes the decomposition process of the value function into separate attributes, where each attribute corresponds to an objective or value; this enables the ability to rank the value of each outcome for each attribute separately [2]. The value function is the preference of extent of goal achievement. The goals are what we want to achieve [2]. The objective is the direction in which we want to go, in order to achieve the goal

\section{Table 1: Description of MAUT Approach}

Goal

\begin{tabular}{ll}
\hline \multicolumn{2}{c}{ Perspective I } \\
\hline Objective A & Attribute A1 \\
\cline { 2 - 2 } & Attribute A2 \\
\cline { 2 - 2 } $\begin{array}{ll}\text { Attribute A3 } \\
\text { (Objective A) Preference }\end{array}$ & A1, A3, A2 \\
\hline Objective B & Attribute B1 \\
\cline { 2 - 2 } & Attribute B2 \\
\hline & Attribute B3 \\
\hline
\end{tabular}

Ranking Value Function = Goal (Objective A) Preference

B1, B2, B3 


\section{ANALYSIS}

\section{Coding the data}

The process of organizing, coding, and analyzing of data requires several iterative operations to extract meaning from the data. The coding process of all transcripts was completed by performing preliminary coding which included data exploration and data reduction techniques, such that the researcher assigned words to segments of text, then data "linking" [15] or connecting relevant data segments to each other, and finally associating decision analysis techniques to the data to determine patterns and themes, segregating and categorizing based on perspectives, attributes, and goals. For this study, the data analysis and data collection activities were performed in concert to avoid the risk of repetition and to maintain focus [3] as noted in Table 2.

Table 2: Analysis

Goals Forming the IT Professionals' Perspectives on Employing Server Virtualization Technologies

\begin{tabular}{|c|c|c|}
\hline $\begin{array}{l}\text { IT Professionals' } \\
\text { Perspectives }\end{array}$ & Goals Category & $\begin{array}{l}\text { Associative (Attributes) } \\
\text { Word or Phrases }\end{array}$ \\
\hline Operational Perspective & $\begin{array}{l}\text { This perspective concerns the integration } \\
\text { of IT into the organization and the role IT } \\
\text { plays in process coordination and } \\
\text { integration between the organization and } \\
\text { its counterparts. }\end{array}$ & $\begin{array}{ll}\text { - } & \text { Reducing server operational maintenance } \\
\text { - } & \text { No need for fully redundant systems } \\
\text { - } & \text { Improving server utilization rate } \\
\text { - } & \text { Enabling the need for physical servers } \\
\text { - } & \text { Reducing provisioning and the deploying of new } \\
\text { applications or services }\end{array}$ \\
\hline Benefits Perspectives & $\begin{array}{l}\text { This perspective includes the tangible and } \\
\text { intangible benefits derived by IT } \\
\text { implementation. }\end{array}$ & $\begin{array}{ll}\text { - } & \text { Cost savings } \\
\circ & \text { No hardware procurement costs } \\
\text { - } & \text { Cost reductions } \\
0 & \text { Lower support cost } \\
\circ & \text { Lower power consumption } \\
\circ & \text { Lower software licensing agreement }\end{array}$ \\
\hline $\begin{array}{l}\text { User Orientation } \\
\text { Perspectives }\end{array}$ & $\begin{array}{l}\text { This perspective concerns the value of an } \\
\text { IT system/tool and is based largely on the } \\
\text { extent to which it helps the user do its job } \\
\text { more efficiently. This impacts the } \\
\text { transparency to the user. }\end{array}$ & $\begin{array}{ll}\text { - } & \text { Reducing application down time } \\
\text { - } & \text { Improving application process time } \\
\text { - } & \text { Agility (ability to move application to another server) }\end{array}$ \\
\hline $\begin{array}{l}\text { Strategic } \\
\text { Competitiveness } \\
\text { Perspective }\end{array}$ & $\begin{array}{l}\text { This perspective focuses on the long range } \\
\text { strategic goals. It supports competitive } \\
\text { advantage in the future }\end{array}$ & $\begin{array}{ll}\text { - } & \text { Quick hosting of application } \\
\text { - } & \text { Support non-production environment } \\
\text { - } & \text { Support migrations to new data centers } \\
\text { - } & \text { On demand computing } \\
\text { - } & \text { Support green initiative } \\
\end{array}$ \\
\hline $\begin{array}{l}\text { Technology/ System } \\
\text { Perspective }\end{array}$ & $\begin{array}{l}\text { This perspective refers to technical } \\
\text { systems (i.e., hardware and software) } \\
\text { which includes reliability, suitability, and } \\
\text { security of the application }\end{array}$ & $\begin{array}{ll}\text { - } & \text { Extending refresh life cycle } \\
\text { - } & \text { Improving security stance } \\
\text { - } & \text { Enabling simple, responsive, utility-style 'cloud } \\
\text { - } & \text { computing' infrastructure } \\
\text { - } & \text { Load sharing and Automatic failover } \\
& \text { Support Disaster Recovery }\end{array}$ \\
\hline
\end{tabular}

RESULTS

What do IT professionals see as the relevant factors influencing their choice to employ server virtualization technologies within an IT organization?

According to the participants in this study, there are five major factors that influence the decisions that the IT professionals make while employing server virtualization technology and these factors influence their decision during the virtualization life cycle as noted in Table 3. 
Issues in Information Systems

Volume 15, Issue I, pp. 418-429, 2014

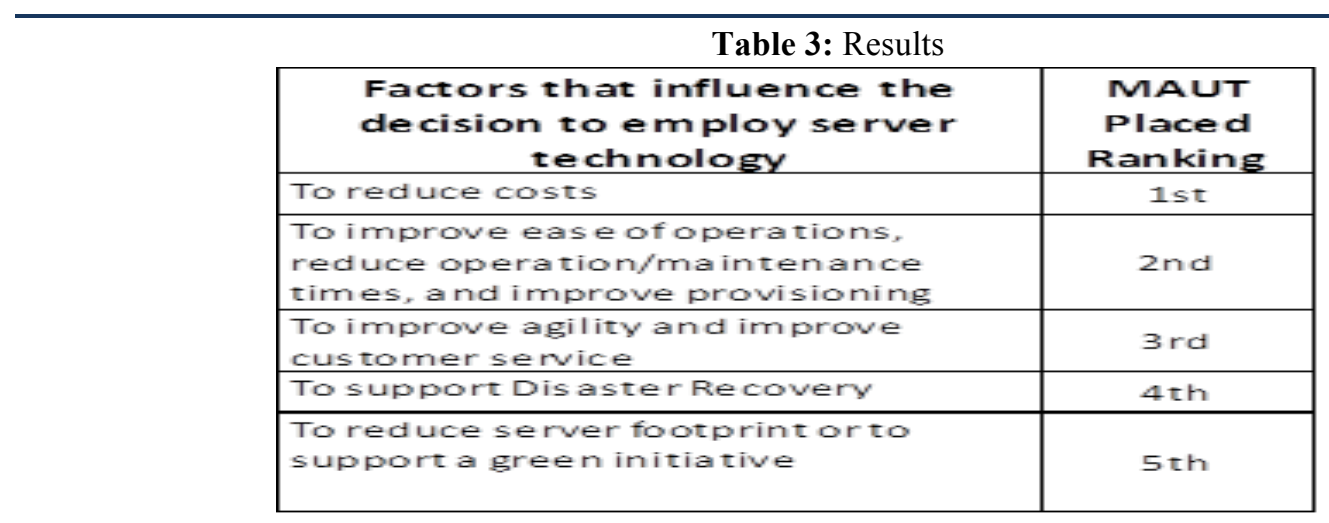

\section{Reducing Costs}

The participants in this study agreed that the use of server virtualization technologies will support their efforts to keep costs low within IT organizations. They indicated that server virtualization technologies will reduce the costs that are associated with activities of procuring a physical server, power consumption, and operational support. The costs associated with the server procurement activity are usually labor costs that include the time IT professionals spend researching and identifying the type of server that fulfills the client application requirements, time spent installing and configuring the server, and time spent managing and reporting on the server status. The cost reductions associated with power consumption include the electricity $(\mathrm{kw} / \mathrm{hr})$ costs for processing the applications. The costs for operational support include labor costs associated with building, migrating, and managing the physical server itself. The participants indicate that server virtualization reduces the time it takes to configure a new server because it does not require all the configuration steps or the cabling requirements associated with installing a physical server. In this study it was interesting to note that only one participant, Participant Seven, a CIO with 25 years of IT experience, indicated that user should consider the total cost of ownership of server virtualization within an organization that includes tangible and intangible costs; such as fixed and variable costs, marginal and sunk costs, and opportunity costs. must be monitored as they occur throughout the life cycle of the virtualized server.

Fixed costs arise from making preparation for the future and are defined as a group of costs in an ongoing activity whose total will remain constant throughout the range of operational activity [29]. Fixed costs are also called set-up, overhead, or first-copy costs [19]. Examples of fixed costs in a virtualization project are machine depreciation, maintenance taxes, least rentals, building, administration expenses (i.e., work done by internal staff to keep the server technology operating), power, the organization's network costs, skilled labor, and ongoing research. To administer server virtualization technologies the operation and maintenance costs which include labor costs of operations personnel, power costs, maintenance supply costs, spare and repair costs, software licenses and server maintenance are all considered fixed costs because server maintenance in a data center is most likely under an existing service plan, which comes in many different forms usually with one of several levels of response time guarantee [14].

Variable costs unlike fixed costs increase as the level of output increases within a given period of time [19]. These costs include hourly wages of IT staff. In general all costs such as direct labor, direct material (i.e., 3-phase power cords), and direct power are allocated to each server, as the servers increase or decrease these costs should change accordingly. Operation and maintenance activities that include maintenance on-call support are considered variable because usually server incidents or problems are resolved within several hours or within the same day. Since, server maintenance is directly associated with individual machines IT organizations usually have no difficulties in establishing these costs. This variable cost also includes labor costs resulting from outside organizations having to perform maintenance services such as running backups on the servers.

Incremental and marginal costs are essentially the same concept, which is an increase in cost in relation to some other factor. For example, if an existing data center hosts twenty clients in the first quarter of 2008 and by the second quarter 2008 hosts twenty-five, the cost of hosting the additional five additional clients are the incremental and marginal costs. These costs may include: additional virtualized servers, virtual machine (VM) software licenses, operations personnel, administration reports, etc. When performing technology or engineering economic 
analyses, the decision maker should concentrate only on the costs that occur in the future and disregard the costs the occurred in the past because these costs cannot be altered by future actions; these costs are called sunk costs. Sunk costs in regards to implementing virtualization technologies include research efforts and proof of concepts that IT organizations conduct as part of their technology evaluation process. Operation and maintenance activities associated with technology phase out and logistics costs are all considered sunk costs because they would occur even if server virtualization is not implemented. However, the results of these research efforts can provide cost avoidance opportunities for future activities.

Finally, opportunity costs are important when evaluating and selecting server virtualization technologies and implementation approaches because that can identify hidden costs associated with all alternative solutions to determine the economically efficient technical solution. For example, if an IT organization selects the OS virtualization approach instead of the hardware emulation approach they will have to consider that the OS virtualization approach only supports hosting the same OS applications and versions. As a result, additional virtualization environments must be implemented if an organization is running multiple OS technologies, thus there are additional costs associated with implementing these additional environments and these costs are called the opportunity costs for implementing the OS virtualization approach. In addition, server virtualization technologies can also reduce or eliminate the costs for maintaining standby hardware, because of features such as VMware's Vmotion that allows virtual environments to be easily moved to other physical machines if the host hardware fails.

\section{Ease of Operations}

The participants in this study indicated that server virtualization offers capabilities that can reduce the time it takes to spin up new applications and manage those that already exist; thereby, reducing the management cost of doing business for IT. This is derived through significant improvements to the speed in which common IT tasks can be accomplished. With the insurgence of application requirements, operational support has increased in complexity over the years and as a result technologies such as server virtualization has lent a helping hand in reducing operation and maintenance times and expediting the application provisioning process and deploying new applications, by: 1) Enabling fully redundant systems, 2) Improving server utilization rate, 3)Improving agility (move application to another server), 4) Reducing the need for physical servers, and 5) Enabling automated data center operations.

In order to achieve the aforementioned capabilities, IT operations organizations must integrate server virtualization technologies into its organization in such a way that it enhances existing current processes but does not negatively impact costs, that it invokes a cultural change that will support strategic initiatives, and that enables the process coordination and integration of technology systems. For example, Participant Eleven, an Architect with 22 years of IT experience, stated: "Server virtualization absolutely spawned new processes. You know, that's one of the mainstays of going into a virtualized environment is that your support platform is changed along with the management requirements associated with how servers are employed and developed. There's also a capacity management piece that needs to be included to make sure that you don't run out of shared storage and you have to add more equipment, that kind of stuff."

\section{Improve agility and improve customer service}

The participants, especially those in the engineering role, indicated that using server virtualization technologies expedites the application server configurations and build process. A rapid server configuration expedites the server availability. In the event that a server fails, an administrator can move a virtual server from one physical host server to another physical host server in about 30 to 90 seconds. However, there is no interruption in availability of the virtual machine at that time. By experiencing no interruptions, the application remains available to the customer and this quick movement (agility) enhances the application reliability and availability and therefore allows IT professionals to swiftly respond to their customers' changing demands. It has been the researcher's experience that server virtualization supports deploying new services as well as scaling those that already exist because of virtualization's intrinsic ability to rapidly deploy configurations across devices and environments. 


\section{Disaster Recovery}

It has been the researcher's experience that server virtualization reduces errors caused by incompatibility of disparate production and recovery hardware, and it makes disaster recovery/business continuity processes (DR/BCP) run faster and easier to verify and test. The researcher participated in numerous DR drills that replicated and easily moved virtual images manually or automatically to a hot, cold, or warm stand-by site, where these images were uploaded and restored at the new site with minimal effort. In this study, because server virtualization technologies can support the reliability, security, availability, and suitability of the clients' applications or processes, the CIO participants identified disaster recovery as their number one influential factor that caused them to employ the technology. However, the researcher found it important to note that the CIOs were not seeking server virtualization to support their mission critical applications that are high volume transactional systems that require having Tier 7 application availability, such as systems that could calculate the biometric metrics of person who is at the border trying to enter in to a country. This Tier 7 application, must maintained at the highest levels of data currency and requires little or no tolerance for data loss - where the rapid recovery of the application is automated, allowing for restoration of systems and applications much faster and more reliable than would be possible through manual Disaster Recovery procedures [30]. Currently, server virtualization technologies do not support multi-processing applications but this did not deter the CIOs away from the use of the technology. The CIOs sought to employ server virtualization in order to support the less than critical (or secondary) system because it helped their clients to perform their jobs better. For example, the secondary application could be an email application server that enables an officer at the border to accept additional information regarding a person in question. This shows that server virtualization technologies have multiple values to users.

\section{Supporting a Green Initiative or Reducing Server Foot Print}

Organizations are supporting green initiatives because their enterprises have hit the limits of their data centers' power, cooling, and space capacity. As indicated in this study, the participants are using server virtualization technologies to create virtual machines to host applications that eliminate the need for using physical servers in some cases. Within a data center, the large number of servers, cabling requirements, and its complex infrastructure are primary drivers of increased energy consumption for power and cooling. For example, if one opens up any IT magazine a data center might be shown that contains racks and racks of servers which can be very hot near the server fans but much colder around the cooling vents, and noisy everywhere. This activity results from removing the heat that the servers produce. The heat comes from the electricity the servers use; however, because the servers consume a lot of electricity IT organizations have initiated green initiatives to reduce the power consumption that can decrease the amount of man-made carbon dioxide emissions the atmosphere. Server virtualization is a technology that can support the IT organization's goal to become more environmentally responsible as well a fiscally responsible within their data centers.

\section{How are decisions made when employing server virtualization technology within an organization?}

In this study, the participants indicated decisions are made in a phased approach throughout the server virtualization employment lifecycle. In the IT organization the server is the fundamental backbone of IT organizations because it hosts critical applications that support a business' ability to meet its goals. For example, at a financial institution the servers could host applications that support major financial systems. These financial systems could be applications that are integrated together to provide automated underwriting capabilities - such as enabling housing counselors to objectively assess whether their clients are ready to apply for a mortgage while taking into account a consumer's credit history and other mortgage options. Since servers play such a vital role within an IT organization, care and caution is required in order to avoid improper manipulation to them which can negatively affect the processing, availability, or capability of an application. Because of the results of this study one should apply a phased approach to decision making [23] when employing server virtualization within an organization in order to capitalize on the benefits and avoid the pitfalls of server virtualization technologies. 


\section{The Server Virtualization Life Cycle Methodology}

Phase 1- Initiation: This phase, also called Pilot/Use Cases, identifies the goals or determines the requirements that the organization wants to achieve. Thus, the questions that should be asked are as follows: What do we want to accomplish with employing server virtualization? What are the virtualization features that we want to enact?

Phase 2 - Plan \& Design: This phase plans and designs how the server would be configured. Thus, the questions that should be asked are as follows: How do we want to accomplish the goals of server virtualization? What environments should I put the server virtualization in? Where do I store the virtual machine?

Phase 3 - Build: This phase configures the virtual machine. Thus, the question that should be asked is as follows: How do I implement server virtualization to accomplish the goals?

Phase 4 - Migrate: This phase transitions from physical to virtual servers. Thus, the questions that should be asked are as follows: When do I deploy server virtualization? What resources do I use to support the server deployment activities?

Phase 5 - Manage: This phase manages, monitors, and reports the activity of the virtual machine. Thus, the questions that should be asked are as follows: Am I meeting the goal that I established? If yes, continue to manage. If not, should I reconfigure the VM? Did I label my virtual servers by application, so I can find them?

Phase 6 - Repurpose: This phase reuses the virtual machine. Thus, the questions that should be asked are as follows: Do I have new goals that the VM can support? Is the patch level on the server up to date?

Phase 7- Retire: This phase sets an expiry date on the virtual servers that have been inactive. Thus, the questions that should be asked are as follows: Has the virtual server been inactive for a set period of time? If so, what is delaying retirement?

\section{The use of the Multi-attribute Utility Theory (MAUT) describes the current server virtualization decision practices}

Based on the results of this study, applying MAUT does describe the current server virtualization decision practices when IT professionals seek to achieve cost reductions and to ease the operational support activities. The fact that the rankings for the "To Reduce Cost" and "To Ease Operations," of the influential factors were the same depict that IT professionals, despite their role, perceive server virtualization technologies as operational tools that can aid IT organizations in experiencing cost savings. MAUT has allowed the decision makers to articulate the options considered as well as the value of these options. When options were considered (clustering, purchase a new physical server, resource management tools and implementing a blade server, and server virtualization) server virtualization was usually ranked higher or the preferred option. The results of this study regarding the influential factors have different influential factors (i.e., goal and values) that correlate to the IT professional roles within an organization. Hence, the differences in the influential factors rankings depict the differences in the perceived role that the server virtualization tool plays within an organization.

\section{CONCLUSIONS}

Corporate executives, corporate strategic planners, and technologist are increasingly turning their attention to opportunities for achieving competitive advantage through information technology and making potential uses of information technology as competitive weapons to incite many to offer opinions seeking IT tools that ease operations, support strategic initiatives, reduce costs, and to allow employees to do their job better. The results of this study indicate that IT professionals perceive that server virtualization technologies as a competitive weapon within their organizational tool kit. This study's results also indicated that IT professionals perceive that server virtualization, as a toolkit weapon can play different roles depending on the battle (or goal). Server virtualization literature abounds with a number of capabilities but the participants in this study warn of the improper employment of server virtualization as it can cause negative effects on critical applications within a business. As a result of using a qualitative approach, this study identified a framework that identifies how to properly employ server virtualization technologies within an organization. This 7-step framework encourages the server virtualization practitioner, at each phase to make decisions throughout its lifecycle.

Prior to this study it is important to note that subject matter experts perceived server virtualization technology as an operational tool, but because of the results of this study and the use of grounded theory the researcher was able to get beneath the surface of social and subjective elements by performing multiple stages of data collection and coding 
refinement activities in order to collect rich data that suggest that server virtualization technology is perceived to have tangible and intangible benefits, strategic, user-oriented, technological as well as operational values.

\section{REFERENCES}

1. Arregoces, M., \& Portolani, M. (2007) Data center fundamentals. Indianapolis, IN: Cisco Press.

2. Baron, J. (2000). Thinking and deciding. (3rd ed.). New York: Cambridge University Press.

3. Bloomberg, L. D. \& Volpe, M. F. (2008). Completing your qualitative dissertation: A roadmap from beginning to end. Los Angeles: Sage Publications

4. British Computer Society (2005). What is an IT Professional? [Online] http://www.bcs.org/server.php?show=conWebDoc.2959

5. Buytaert, Dittner, Garcia \& et, al. (2007). The Best Damn Server Virtualization Book Period. Burlington, MA: Syngress, Inc.

6. Chavence, R. (2005). Server Architecture: Multiprocessors, Clusters, Parallel Systems, Web Servers, Storage Solutions. Burlington, MA: Elsevier Digital Press

7. Citrix Systems. (2008, March 09). A pragmatic approach to server and data center consolidation [White paper.] Retrieved from http://whitepapers.techrepublic.com.com/abstract.aspx?docid=353466

8. Copernicus Consulting. (n.d.).Sampling in Qualitative and Quantitative Research. Retrieved February 7, 2010 from http://www.slideshare.net/sladner/sampling-methods-in-qualitative-and-quantitative-researchpresentation.

9. Corbett, Edward P.J. \& Eberly, R.A. (2000) The Elements of Reasoning. (2nd ed.). New York, NY. Longman Pub Group.

10. Corbin, J., \& Strauss, A. (2008). Basics of qualitative research (2nd ed.). Thousand Oaks, CA: Sage Publications.

11. Creswell, J. W. (2003). Research design qualitative, quantitative, and mixed method approaches (2nd ed.). Thousand Oaks, CA: Sage Publications.

12. Denzin, N., \& Lincoln, Y. W. (2003). Collecting and interpreting qualitative materials. Thousand Oaks, CA: Sage Publications.

13. Dryer, J. S. (2005).MAUT - Multiattribute utility. In Multiple criteria decision analysis: State of the art surveys (pp.265-292). New York: Springer.

14. Golden, B. (2008). Virtualization for Dummies. Hoboken, NJ: Wiley Publishing, Inc.

15. Hesse-Biber, S. N .\& Leavy P, (2006). The Practice of Qualitative Research. Thousand Oaks, CA: SAGE Publications.

16. Haight C., \& Hammond S. (2009).Virtualization, Cloud Computing and the IT Service Catalog: for Scale Inc. TechTarget Retrieved from SearchServerVirtualization.com.

17. IBM. (2006, December). An examination of server consolidation: trends that can drive efficiencies and help businesses gain a competitive edge. [White paper.] Retrieved from http://www03.ibm.com/systems/resources/systems_virtualization_pdf_GSW00579-USEN-00.pdf

18. Keeney, R. L., \& H. Raiffa. (1976) Decisions with Multiple Objectives. John Wiley and Sons, New York

19. Kingma, B. R. (2001). The Economics of Information. (2nd. ed). Westport, Connecticut. Greenwood Publishing Group.

20. Marshall, M.N. (1996). Sampling for qualitative research. Family Practice. 13(6), 522-525

21. Patton, M.Q. (2002). Qualitative evaluation and research methods (3rd ed.). Thousand Oaks. CA: Sage.

22. PMI (2003). Organizational Project Management Maturity Model: Knowledge Foundation. Project Management Institute: Newton, PA USA.

23. Radcliff, D. (2008, August 18). The life and death of a Virtual Machine. Network World, 25( 32),

24. Schreck. G., Lambert, N., \& Nelson, L. (2008, September 30). Inquiry spotlight: Server virtualization, Q3 2008, Forrester Research, Inc.

25. Sligh, D. (2010). Perspectives of IT professionals on employing server virtualization technologies. (Order No. 3435747, Robert Morris University). ProQuest Dissertations and Theses, , 160. Retrieved from $\mathrm{http} / / /$ search.proquest.com/docview/816043421 ? accountid=28365. $(816043421)$.

26. Steinder, M., Whalley, I., \& Chess, D. (2008). Server virtualization in autonomic management of heterogeneous workloads. ACM SIGOPS Operating Systems Review, 42(1), 94-95. 


\section{Issues in Information Systems \\ Volume 15, Issue I, pp. 418-429, 2014}

27. Stewart, R. (2007). A framework for the life cycle management of information technology project ProjectIT. ScienceDirect International Journal of Project Management, 26 (2008), 203-212

28. Sun, K. (2003). IT Roles and IT People an IT Managers Perspective. ISECON: 20. SanDiego CA

29. Thuesen, G.J. \& Fabrycky W.J. (1984). Engineering Economy. (6th. ed). Englewood Cliffs, NJ. PrenticeHall.

30. Warrick, C. (2003, December). IBM: Seven Tiers of Disaster Recovery http://www.redbooks.ibm.com/abstracts/tips0340.html 